\title{
Meninos, eu vi e ouvi!
} (Um depoimento)

\author{
Aluizio R. Trinta*
}

\section{RESUMO}

Herbert Marshall McLuhan e o Centro para a Cultura e a Tecnologia da Universidade de Toronto (Canadá). Origens artisticas, literárias e filosóficas do mcluhanismo (ou do "mcluhnatismo", segundo adversários). Memórias de um jovem professor brasileiro: conhecendo um Mestre. Anotaçōes filológicas acerca dos modos de pensar, escrever e dizer de Herbert Marshall McLuhan.

\section{ABSTRACT}

llerbert Marshall McLuhan and the Center for Culture and Technology at the University of Toronto (Canada). Recollections brought to a young Brazilian teacher's mind. Portrait of a remarkable professor as an artist: mcluhanism (or mcluhnacy?). Philological notes on Marshall McLuhan's ways of thinking, writing and saying.

Aluizio Ramos Trinta Doutor em Comunicação e Cultura pela ECO/UFRJ: Professor dos cursos de Graduação da ECO/UFRJ. 
"McLuhan reads books". Em traços firmes, uma mão apressada assim escrevera em um tapume erguido nas proximidades do Centre for Culture and Technology at the University of Toronto, no Canadá. Ato pensado e ação significativa, provavelmente consciente e reveladora de amplo conhecimento de causa: naquela modesta casa de dois andares havia um gabinete de trabalho revestido por estantes abarrotadas de livros. Ouvia-se ainda dizer que o Centro para a Cultura e a Tecnologia, inaugurado em 1964 pelo Professor Herbert Marshall McLuhan, resumia uma instituição "off campus", dados o seu desalinho intelectual e, certamente, a sua localização em Queen's Park Crescent, um aprazivel jardim público, arborizado com bordos ${ }^{1} \mathrm{e}$ cercado por avenidas de intenso tráfego de automóveis. Em outros tempos, o prédio havia abrigado uma cocheira - "a cool coach house" ", na gíria dos estudantes da $U$. of T. naqueles anos - vindo, posteriormente, a servir como um laboratório de idéias. A H. M. McLuhan, seu diretor desde a inauguração, alguns de seus detratores se referiam como "arauto do fim da cultura livresca". Daí a irônica remissão do grafito.

Nas salinhas do Centro, o Professor McLuhan organizava e conduzia seminários - aos quais, bom sofista, denominava diálogos - para estudantes de pós-graduação em quaisquer áreas, assim como para leigos interessados... e, a seu critério, interessantes, tais como a um ou dois, que me lembre, aos quais H. McLuhan chamou de "cultural adventurers". Em realidade, estes estimulantes encontros intelectuais comporiam um 22 happening, ${ }^{3}$ termo comum naqueles anos e que, hoje, talvez se pudesse traduzir por "o que vai rolar por aí" ou "acontecimento performático".

Estávamos em 1967. Formado em Letras e Literaturas, pela antiga Faculdade Nacional de Filosofia da extinta Universidade do Brasil, eu havia viajado para o Canadá a convite do Departamento de Cooperação Intelectual do Ministério das Relações Exteriores do Brasil, em convênio com o Department of Italian and Hispanic Studies da Universidade de Toronto, para integrar, na qualidade de Professor-Leitor, um programa de Estudos Latino-Americanos então desenvolvido por aquela universidade. $O$ que conhecia do pensamento de M. McLuhan me havia chegado, ainda no Brasil, pela leitura de artigos do Quarto Caderno do extinto Correio da Manhã, com as prestigiosas assinaturas de Haroldo e Augusto de Campos, além de Décio Pignatari. As proposições do professor canadense convinham admiravelmente à formulação de premissas teóricas e de procedimentos práticos da poesia verbi-voco-visual, preconizada pelo Concretismo. Quero crer que Haroldo de Campos tenha conhecido pessoalmente ao Professor McLuhan, com ele compartindo notório interesse pela poesia de Stéphane Mallarmé (1842-1918) ${ }^{4}$.

Transcorreram um ou dois anos até que, tendo dele muito ouvido falar (bem e mal), eu viesse a conhecer de perto ${ }^{-} e$, sem que pudesse de algum modo sabê-lo, preparar-me para dar este modesto testemunho - àquele 
professor de Inglês do Saint Michael's College, uma das mais destacadas unidades de ensino da Universidade de Toronto.

Críticos europeus o chamavam, com algum desapreço por uma identidade nacional em vias de afirmação, de "pensador canadense", embora a si próprio M. McLuhan chamasse, substantivamente, "professor"; despistados, até mesmo jornalistas canadenses a ele se referiam, em seus jornais, como sendo "um filósofo cujas idéias nem sempre são prontamente assimiláveis". ${ }^{6}$ Confesso ter experimentado um fascinio intelectual por aquele professor alto, magro, de andar lento, algo desengonçado, e voz de forte timbre, abaritonada; sua "descontraida seriedade" estava em franco contraste, tanto com a expressão relaxada, tirada a un certo casual style, observável em alguns professores, quanto com a sisudez de outros, entre os quais se alinhavam eminências intelectuais da $\mathrm{U}$. of $\mathrm{T}$., como o teórico e crítico de arte literária Northrop Frye.

"Canadense da gema", Herbert M. McLuhan fizera seu Mestrado na Universidade de Manitoba, concluindo seus cursos em 1934. Naquele mesmo ano, seguiu para Cambridge, na Inglaterra, matriculando-se no Trinity College; influenciado pelo movimento do New Criticism literário, lá apresentou, no ano de 1943, uma Tese de Doutorado em Literatura Inglesa, sobre a obra de Thomas Nashe. ${ }^{7}$ Nos EUA, foi professor da Universidade de Wisconsin, tendo aí feito sua conversão ao Catolicismo Romano e entrado em contato com a cultura pop norte-americana, uma expressão cultural da midia para amplo uso social; a crer-se em suas declarações, ele havia percebido que, para ensinar o que quer que fosse a seus alunos, necessitava imergir em seu "universo de referências", dominar seu repertório básico. Transitaria, então, célere, da "galáxia de Gutenberg" à "galáxia de Marconi", em nave movida a circuitos integrados.

Seu notável domínio de distintos registros de fala da língua inglesa era consciente e informado, até pelo fato de ter ele adotado o método do close reading (algo como uma leitura imanente do texto, a ele se concedendo primazia) de autores como Lewis Carroll (1832-1898) ou, mais ainda, James Joyce (1882-1941). Dos Simbolistas, herdaria o gosto pela figuração metafórica. O Professor McLuhan conhecia as técnicas e admirava as intenções artísticas destes e de outros autores, tais como Percy Wyndham Lewis (1882-1957) e suas "paródias estilisticas", proporcionadas pela compressão de palavras e

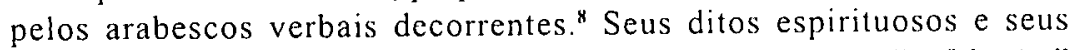
elaborados trocadilhos não provinham do que então se chamava "soft brains" ("miolo mole"); eram, antes, prova de envolvimento intelectual. Brincava com os significantes (sensorialidade) para mais bem desfrutar dos significados (conceitualidade), pondo-os, renovados, a serviço de uma lição original (preceitualidade). A este respeito, creio mesmo tê-lo ouvido dizer (ou assim o entendi) que o jogo-de-palavras ${ }^{9}$ consolida o pensamento da mesma forma 
como a terraplanagem alinha o leito em que se vai assentar uma auto-estrada. É, portanto, provável que o Finnegans Wake, de James Joyce, lhe tenha fornecido a rota de suas explorações. Como explicar, de outro modo, que reproduzisse, com pertinência e oportunidade, seu bordão "The medium is the message" em variações tais como "The medium is the massage" $\mathrm{e}$ "The medium is the mass age"?

Sua presença, em uma acanhada sala-de-aula no andar térreo do Centro, era bem pouco convencional. Tido e havido, no mundo anglo-saxão, como um "intelectual revolucionário, em vias de tornar-se uma personalidade carismática", o Professor McLuhan talvez merecesse ser chamado de "mago" ou "professor de um novo tempo", uma vez que o final da década de $60 \mathrm{e} \mathrm{a}$ década seguinte ficariam conhecidos como tempos da "contracultura", do "movimento underground". Um quarto $M$ vinha juntar-se a outros três, todos designativos de "ícones sagrados" do pensamento anti-establishment, da indignação filosófica ou do inconformismo moral: Marx, Mao, Marcuse e, por fim, mas não com menor importância, $M$ cLuhan. Um tempo propício à irreprimível fascinação por tudo o que, proxima ou remotamente, pusesse em xeque conceitos e certezas firmados, assim como teorias desenvolvidas e sistemas metafísicos consagrados, nos quais, até então, o Ocidente se havia alicerçado. Entre o que se tinha por dogmas, truísmos talvez, figurava a prevalência da escrita (manuscrita, mas também tipográfica) de base alfabética; e, por via de conseqüência, o livro. "Há mais vida [para viver] do que livros [para ler]", repetia, enfático, o Professor McLuhan.

Impossível fazer anotações lineares ou cursivas, sem esforço e com rapidez, dos autênticos festins intelectuais em que se convertiam as aparições do professor. Tampouco havia na sala quem portasse gravadores de áudiocassete para registrar sua inspirada fala. "No recording, please!", ele polidamente pedia. Era bem provável que gravar a sessão de pouco ou nada valesse: à saída, cada um de nós lembraria apenas de um ou outro vislumbre poético, frase sentenciosa ou dito oracular do Professor McLuhan. Dentre os que o ouviam, havia muitos que, com honesta devoção e fervor intenso, o consideravam um guru — termo sânscrito que tem por significado "professor da alma".

Eu me apressei a ler os seus livros, tendo começado por The Mechanical Bride; folklore of industrial mañ. Sob meus olhos, um interessante estudo sobre o impacto da publicidade na sociedade e na cultura. Cheguei a colecionar alguns números de Explorations, revista que $\mathrm{M}$. McLuhan e Edmund Carpenter, um de seus mais próximos colaboradores, haviam fundado em 1953, dedicando-a a estudos de linguagens da mídia. Com olhar admirativo, percorri as páginas de Understanding Media; the extensions of man: aprendi que o fato essencial da comunicação é a própria comunicação, de par com os seus media (linguagem, dinheiro, impresso, disco, moda, automóvel, televisão) e não tanto a mensagem transmitida. A mensagem 
ou "massagem (psicossocial)", tida por conteúdo da comunicação, é um engodo hábil, que distrai nossa atenção enquanto o medium sobre nós exerce uma ação tanto mais profunda, quanto menos temos condições de dele dar alguma conta. Li os que se seguiram, tais como The medium is the massage; an inventory of effects, publicado em 1967.

Uma vez justapostos, os livros, os artigos e as incontáveis entrevistas que o Professor McLuhan concedeu encerram contradições. Sua obra não configura nem manifesta um corpo doutrinário preciso. Todas as contas feitas, ele não tencionava corresponder ao "homem de Gutenberg", a quem definia como "explícito, lógico, literal"; e, mais ainda, como "pontual", "produtivo", "pragmático". Bem ao contrário, tudo o que queria era proceder filosoficamente pelo que ele próprio denominava probes. ${ }^{10}$ Herbert Marshall McLuhan se esforçava por apreender a realidade de seu tempo, pondo em relevo sua complexidade intrínseca para logo restitui-la sob forma de um mosaico brilhante. "I don '́ explain, I explore", repetia, enfático; "I may be wrong. but I'm never in doubt". O explorador, como o viajante, tem muito de um ser errático, ilógico: um e outro nem sempre sabem onde estão, nem imaginam que possam estar prestes a fazer uma descoberta. A exploração vale uma aventura.

$\mathrm{Na}$ falta de um pensamento propriamente cartesiano, que se pudesse ter na conta de rigoroso, suas idéias, uma vez dadas a conhecer, se prestavam a múltiplas e variadas explorations (outro termo pelo qual manifestava predileção), obrigando a seus comentaristas e críticos, indo bem além do que se pudesse ter por uma "linha de pensamento", a desenhar os contornos do que, em seu caso, efetivamente constituísse uma disposição natural, uma propensão, uma tendência. McLuhanism ou McLuhnacy?

Seu estilo de escrita era terso, tenso, epigramático. Denso como qualquer aforismo. Havia, afinal, mil e uma maneiras de responder não respondendo. Similes precisos e parábolas insinuantes eram o seu forte: umas tantas formas literárias de nada dizer diretamente, tudo dizendo, porém, em clima de baixa temperatura informacional. "Cool sayings". Sua coerência não estava no que ele, arguta ou astutamente, enunciava ou parecia estar expondo; tampouco em posições tomadas, por vezes incompreensiveis. "I' $m$ not an arsonist", afirmava, rebatendo acusações de que, espontaneamente, transigia com "profecias auto-realizadas".

Tendo trocado o ponto-de-vista firmado pela estimativa de interfaces, o Professor McLuhan apreciava o recurso a citações, em genuina messe intelectual a serviço de uma interpretação inovadora. Ele fazia brotar a verdade dos fatos de que se ocupava, escandalizando o leitor ou o ouvinte com suas afirmações terminantes. Servida por uma formidável erudição, a prospecção pela qual tanto se empenhou logo daria bons frutos, abrindo-se em modos novos de ver e de pensar. Marshall McLuhan não parecia nutrir maior interesse pela comunicação, aqui entendida como processo de transferência e transmissão de conteúdos; seu entusiasmo ia para a informação, isto é, aos 
padrões próprios a uma organização programada de certo número de dados. Ele dizia dedicar-se a observar, poeticamente, as transformações assim operadas: o princípio da inteligibilidade de um novo tempo estaria na atenta consideração de um "pattern recognition" ou, por outras palavras, em modos atuais de perceber e captar "esquemas de informação". As soluções dos problemas somente poderiam vir em linha com os padrões que os definissem e, portanto, os determinassem.

Entre os maiores méritos de McLuhan estará o de ter sido um homem de seu tempo. Por açodamento, talvez, pouco apuro e muito desdém, dele pretenderam fazer o "profeta de um tempo futuro", dado o tom algo bombástico de suas intervenções. Daí à constituição de um "mito vivo" era um passo, que, ao que parece, foi dado. Ainda que, às vezes, se deixasse mitificar pela mídia e pelas grandes corporações, entre as quais a universitária, Herbert Marshall McLuhan se votou ao estudo do presente, tendo, porém, o cuidado de pôr de lado espírito, hábitos mentais e visão rígida - a dos "espelhos retrovisores" ("rear view mirrors") - para enxergar a face cintilante das tecnologias emergentes, sem temê-las e, tampouco, sem lhes voltar as costas. "Todo envolvimento [participação sensorial acentuada] é muito legal", dizia, utilizando o adjetivo "cool" " em seu sentido gírio, como então era corrente. $O$ professor canadense acolhia as descobertas de seu tempo com lúcido candor: de modo consciente e intencional, ele se recusava a moldar ou emoldurar os achados do presente ao talante de tremores e temores do passado. Não recusava o curso da História; julgava, isto sim, necessário considerá-lo sob perspectivas radicalmente inovadoras. A lucidez inconteste do Professor McLuhan provinha, sem dúvida, do fato de ele dimensionar, com inteira pertinência, tanto efeitos benéficos, quanto ameaças potenciais que tais descobertas comportassem. Em nada laudatório ou "integrado", o "Mind your media, men!" era um de seus brados de alerta.

$\mathrm{O}$ ano de 1980, em cujo curso desapareceram Roland Barthes, Jean Piaget e Erich Fromm - e, entre nós, Hélio Oiticica e Vinícius de Moraes fecharia com mais uma nota triste. No dia 31 de dezembro, calou-se o Professor Herbert Marshall McLuhan.

Sim, McLuhan lia (e muito a muitos) livros. Sabia ler e, de maneira criativa, se apropriava do que lia. Onde mais encontrar a seiva nutriente de um pensamento original?

\section{Notas}

'.O bordo (árvore da família Acer) é o maple ou érable canadense, aqui mencionado nas duas línguas institucionais do Canadá. Símbolo nacional, a folha de bordo (maple leaf) figura na bandeira deste país, ocupando, emblematicamente, seu centro. $O$ xarope de bordo (maple syrup), seiva açucarada desta árvore, é rico em sacarose, servindo a um ritual culinário: o canadense dele se serve para cobrir as panquecas que prepara para o café-da-manhã. 
${ }^{2}$ No interior de uma das pequenas salas do referido Centro, via-se, na parede, um mural intitulado "Pied Pipers All", do artista plástico René Cira. Estes tocadores de gaitas de fole multicoloridas, que figuram como pano-de-fundo $\mathrm{cm}$ tantas fotos de M. McLuhan, feitas por ocasião das quasc incontáveis entrevistas que ele concedeu - compunham uma representação estilizada de uns tantos robôs simbólicos, bem como de alto-falantes e, sobretudo, de uma tela de telcvisão, ocupando o centro geométrico. Havia aí uma forte sugestão de movimento repentino, voraz, abismal. A televisão, disse ele uma vez, "is a Pied Piper and we forgot to pay the piper". Era mesmo preciso prestar atenção à espetaculosa e multicolorida TV, em sua centralidade moderna. Pagar para ver. No início dos anos 70, o Professor McLuhan tcve de afastar-se para assumir a Cátedra de Humanidades Albert Schweitzer, na Fordham University em Nova Iorque. De certo modo, cra como se a mão-de-direção cultural da América do Norte estivesse sendo invertida, indo da tundra canadense à pradaria americana. Uma movimentada housewarming, com jogos, brincadeiras e a presença de personalidades do tout Toronto, acolheu e deu as boas vindas ao Professor Arthur Porter, que lá ficaria por dois anos.

${ }^{3}$ Naqueles anos, denominava-se happening a um espetáculo dramático que tinha lugar ("acontecia") de modo imprevisto; havia sido concebido e seria apresentado como uma seqüência de ocorrências sem elos entre si e sem continuidade. A espontaneidade desta apresentação garantia a surpresa divertida e um intenso envolvimento sensorial por parte da platéia. "Cool, man!" ("Legal, cara!") repetiriam, encantados, os que a assistiam.

${ }^{4}$ Importante movimento estético da literatura e das artes visuais, o Simbolismo fazia valer o mote "definir é matar; sugerir é criar". Por ele, as idéias deveriam vir expressas por meio de símbolos ou de sugestivas alusões, jamais por mcio de afirmações conclusivas. "I avoid concepts and work on precepts", dizia o Professor McLuhan. Ao prefcrir o preceito (a lição, o mandamento, a doutrina) ao conceito (autoritário e rígido) ou à noção (tenra e macia), H.M. McLuhan firmava sua reputação como preceptor ou mentor ("aquele que inspira, estimula, cria ou orienta idéias, ações e projetos"). E, como um excmplo vale mil ensinamentos, tratava ele de, sem qualquer esforço aparente, assim se apresentar.

5 "Canadian" queria dizer "other American", um "americano de um outro tipo" ou de "outra linhagem". Herbert Marshall McLuhan afirmava ser "Canadian to the core", à diferença de, pelo menos, outras duas personalidades canadenses - o jazzman Oscar Peterson e o economista John Kenneth Galbraith - que, tanto quanto se sabe, jamais fizeram questão de declinar sua nacionalidade original. Católico em uma nação protestante, M. McLuhan, quando de sua estada na Inglaterra, se havia intercssado pelo pensamento do escritor católico inglês Gilbert Keith Chesterton (1874-1936), um autor de estilo vigoroso que iria distinguir-se por suas incursões no romance policial, pondo em cena 'Father Brown', um padre-detetive. Como seria de se imaginar, estaria aqui uma adequada metáfora para a sondagem informada, a pesquisa exploratória c a detecção esclarecida. Um investigador profissional está preparado e disposto a efetuar uma perquirição meticulosa, profunda, rematada. E, acima de tudo, inventiva, como se verificava no caso de Marshall McLuhan. 
${ }^{5}$ Os jornais e revistas que, naqueles anos, circulavam em Toronto nem sempre entendiam bem o que, em registro culto e até literário da língua inglesa, Marshall McLuhan expressava com a desenvoltura de sempre. "Best known Canadian citizen to the world at large", titulou certa vez, no início dos anos 70, o Toronto Daily Star; adiante, podia-se ler tratar-se de um "professor, prophet, poet and provocateur", em referência ao fato de que Herbert Marshall McLuhan era "a requested lecturer around the world". A crítica, não raro, vinha sob a forma de manchetes, tais como "enigmatic McLuhanisms have become international catch phrases", seguindo-se, no corpo da matéria, a citação de alguns probes do professor canadense. Entre eles, três dos mais conhecidos: "Nudity is sculptural, not visual" (Alguém irá lembrar-se de um espetáculo teatral off Broadway intitulado Hair?). "The audience is the show", uma referência ao impacto da TV, precedia à expressão poética de uma realidade tecnológica: "We live in a global village". O mundo "encolhia" em virtude da transmissão, por satélite, de sinais de TV. Lotta Dempsey, à época prestigiosa colunista do matutino Toronto Daily Star, escreveu que, após ouvir a fala clara e desassombrada de Marshall McLuhan, teve a sensação de que, finalmente, "acabara de sair de uma galeria de espelhos deformantes".

${ }^{7}$ Autor satírico inglês de fins do século XVI. Escrevia panfletos em tom mordaz, nos quais fazia valer uma forma de humor tipicamente anglo-saxônica, o wit. Humor cáustico com o qual podem ser feitos comentários levemente irônicos ou francamente depreciativos, o wit se expressa em engenhosas comparações e hábeis contrastações, para as quais é requerida extrema destreza na concepção e na prática do jogo-depalavras.

${ }^{8}$ Pintor, romancista e crítico inglês, P. Wyndham Lewis foi um experimentalista, comparável, em alguns aspectos, a James Joyce. Em 1913, esteve à frente do Vorticismo, movimento artístico que propugnava por uma arte abstrata, tendo por base plástica, a disposição concêntrica de figuras, como se estivesse em um vórtice ("redemoinho" ou "turbilhão"). (Veja-se a referência feita ao mural de René Cira). Herbert Marshall McLuhan fez incontáveis alusões ao que chamava de um "tremendous vortex of power", para dizer do sorvedouro (" $a$ violent and destructive force") em que se estava transformando a mídia eletrônica moderna. Descrevia tanto o "poder consumidor de um vórtice", quanto mencionava a "um vórtice de espantoso vigor" - um c outro metáforas bem ajustadas a uma referência ao rápido movimento de rotação em espiral, que a tudo submete e termina por engolfar. Em variação livre no que tange a este modo de dizer, o Professor McLuhan fazia, constantemente, uso estilístico da imagem do maelström, com ela designando o "giro vertiginoso" ou o "tumultuado volteio" da ambiência midial, em suas inexoráveis incidências na sociedade, na arte, na cultura e no pensamento.

${ }^{9} \mathrm{Um}$ trocadilho resulta de uma semelhança fônica de duas palavras distintas, de resto, quanto a seus significados e à sua grafia. Ludismo verbal próximo à charada, algo como um enigma sonoro, o jogo-de-palavras se apóia, ora na paronímia, ora na homonimia, ora, ainda, na homofonia, produzindo sugestivos efeitos de sentido. A "alocução bem humorada" é um deles. Tomemos, como exemplo imediato, seu nome, Marshall, "marechal" ou "mestre-de-cerimônias", mas também "chefe de polícia", em sua forma substantiva; e como verbo, to marshall significa "arrange in proper order". Aos críticos, portanto, era confiada a tarefa de marshalling McLuhan, "alinhar 
em seqüência coerente as idéias de McLuhan". "Read Joyce" e rejoyce soavam, para o Professor, de modo idêntico. E passavam a ter o mesmo significado: "leia Joyce" e "sinta grande alegria", "dê sinais de júbilo", "mostre-se contente". Por quê'? Porque "Finnegan (i)'s awake".

${ }^{10}$ Literalmente, "perfurações feitas $\mathrm{cm}$ um solo de modo a verificar sua composição natural"; "sondagens". Eis alguns exemplos destes "balões-de-ensaio" filosóficos: "If people manifest rage, you get action" (sobre as manifestações de rua), "Only small secrets need to be protected. Great discoveries are protected by people s' disbelief" (há quem pense que o homem jamais foi à Lua). "Cash money is the poor man's credit card" (sobre o "dinheiro de plástico").

1 "Cool" designa, em língua inglesa, "cold to a slight or pleasant degrec". Nem "aquecido", nem "esfriado", uma vez referido a personalidades ou a formas de comportamento, passa a traduzir-se por "unperturbed" ou self-possessed ("senhor de si"), em uma gradação semântica, de importe moral, que vai da "ausência de cordialidade" à "fricza", passando pelo "desinteresse" ou pela "indifcrença". Em acepção de gíria, cool - "Cool it a second, baby", como se dizia, ao tclefone, $\mathrm{cm}$ registro de fala distenso, pedindo-se ao interlocutor que esperasse um pouco - era parte da expressào "keep cool" ou "keep your cool", algo como "fica frio, malandro" ou, de modo mais formal, "fique calmo". Na cidade de Toronto, quando lá vivi, cra muito conhecido e largamente consumido entre os jovens universitários um refrigerantc em pó chamado Kool Aid, do qual alguns diziam ser recomendável (sabe-se lá por quais razõcs) para quem desejasse "fazer a cabeça" ou "desentortar a cuca". Quanto à expressão "cool media" — com a qual se assinala e define uma das dicotomias nodais da obra de M. McLuhan - terá ela, originalmente, provindo do jazz. Em 1945, quando Miles Davis começou sua carreira, tocando ao lado de músicos renomados, tais como Dizzy Gillespie e Charlie Parker, era o bebop com suas harmonias dissonantes o gênero musical prevalente. Em menos de cinco anos, este artista da música integraria a vanguarda, ao propor que o jazz experimentasse o improviso e sc fizesse mais suave, intimista, envolvente. "Birth of the cool", um LP de 1954, resumiria em seu título o que então se passou: com o pianista e arranjador Bill Evans, Miles Davies havia criado o "cool jazz". "Cool media" - a voz, o telefone, as histórias $\mathrm{cm}$ quadrinhos e a televisão aberta - notabilizam-se pela imperfeição, a superficialidade e a baixa definição; e, por requererem intensa participação sensorial do destinatário de suas mensagens, são, paradoxalmente, "quentes". Isto ocorre porque o que $\mathrm{M}$. McLuhan denomina "coof" equivale ao nosso "tropicool", a temperatura informacional dos trópicos, entre os quais nos situamos. "Meios frios" imantam mais do que explicitam; donde o fascínio que jamais deixam de exercer. Herbert Marshall McLuhan era a mensagem. "Cool (,) man!" 


\section{Palavras-chave}

1. Herbert Marshall McLuhan

2. Registros de lembranças

3. Comentários

4. Anotações 